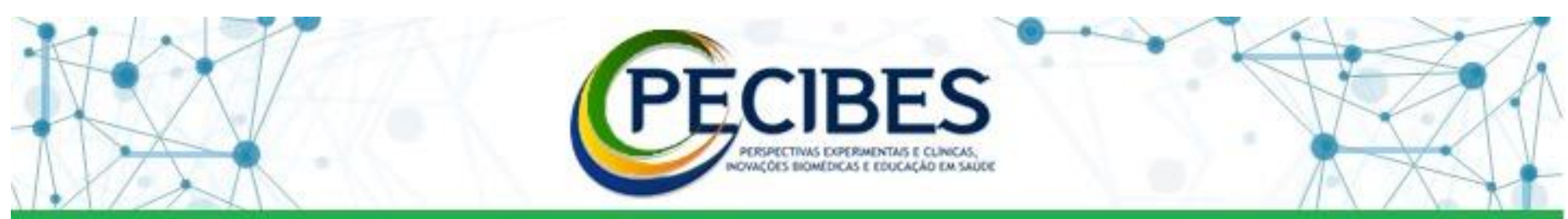

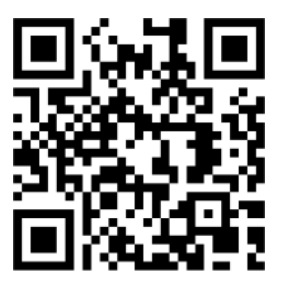

http://www.seer.ufms.br/ind ex.php/pecibes/index

*Autor correspondente: Adalberto Vieira Corazza, Universidade Federal de Mato Grosso do Sul - UFMS. E-mail do autor:

adalberto.corazza@ufms .br

Descritores: Enxerto.

Biovidro.

Fotobiomodulação.

Lesão. Calvária.

Key-words:Graft.

Bioglass.

Photobiomodulation.

Lesion.

Calvary.

\section{Biovidro ativado com colágeno e Laser de Baixa Potência na regeneração de defeito ósseo em calvária de ratos.}

\author{
Bioglass activated with collagen and Low Power Laser in the regeneration of bone defect in \\ rat calvaria. \\ Lukas Monteiro' ${ }^{1}$ Montezzo, D.E ${ }^{2}$, Silva. I.S ${ }^{3}$, Bagnato, V.S ${ }^{4}$, Corazza, A.V ${ }^{5}$ \\ 1.Acadêmico de Medicina, UFMS-CPTL, MS. \\ 2. Médico, UFMS-Curso de Medicina do CPTL, MS. \\ 3. Médica Veterinária, UFMS-FAMED, MS, Brasil. \\ 4. Físico, Instituto de Física de São Carlos/USP, SP, Brasil. \\ 5. Fisioterapeuta, Curso de Medicina do UFMS/CPTL, MS, Brasil.
}

Introdução: A regeneração óssea tem apresentado resultados eficientes com diversos tipos de biomateriais e tecnologias regenerativas. Assim, o presente estudo analisou os efeitos fotobiomoduladores da laserterapia de baixa potência (LLLT) associado ao enxerto de vidro bioativo (BG) e colágeno bovino na proporção mássica de $75 \%$ de vidro e $25 \%$ de colágeno no reparo ósseo em escareação de calvária em ratos. O modelo experimental aprovado pela Comissão de Ética no Uso de Animais (942/2018) consistiu de defeito ósseo circular com broca trefina de 5,0 $\mathrm{mm}$ de diâmetro na região frontoparietal esquerda de 40 ratos. Os animais foram distribuídos aleatoriamente em 4 grupos: Biovidro (BG) com enxerto de Vidro bioativo $58 \mathrm{~S}(58 \% \mathrm{SiO}, 33 \% \mathrm{CaO}$ e $9 \%$ P O em percentual mássico, sendo essa porcentagem dividida em $75 \%$ de $58 \mathrm{~S}$ e $25 \%$ de colágeno, ActiveBone $\left.{ }^{\circledR}\right)$; Laser (L), com $120 \mathrm{~J} / \mathrm{cm}^{2}$ e $780 \mathrm{~nm}$; Laser + Biovidro (LBG), associando as técnicas; e Controle (C), sem intervenções. O enxerto ActiveBone ${ }^{\circledR}$ foi aplicado imediatamente após a lesão óssea e a Laserterapia imediato e a cada 48 horas. A histomorfometria da densidade de volume (DV) vascular, de osteócito e da matriz óssea (MO) foram realizados em 15 e 30 dias após defeito ósseo na calvária, sendo compostas em subgrupos com animais. Os grupos L e LBG foram eficientes na formação de vasos sanguíneos em comparação ao grupo C. O grupo BG, tanto aos 15 e 30 dias demonstraram maior eficiência na formação de matriz óssea e osteócito em relação ao grupo L, LBG e C. Por outro lado, o Laser aplicado isoladamente aumentou a DVMO em relação ao grupo controle $(\mathrm{p}<0,05)$. O enxerto ActiveBone ${ }^{\circledR}$ otimizou a regeneração óssea após 30 dias de enxerto em defeito ósseo de calvária, seguido pela utilização isolada da LLLT, entretanto a associação dos procedimentos terapêuticos não suplementou a DVMO. 